\title{
Persuasive Technology in The Islamic Perspective: The Principles and Strategies
}

\author{
Mohammed Abdullah Bawazir, Murni Mahmud, and Nurul Nuha Abdul Molok \\ Dept of Information Systems, International Islamic University Malaysia, Kuala Lumpur, Malaysia \\ Bawazir333@gmail.com \\ Dept of Information Systems, International Islamic University Malaysia, Kuala Lumpur, Malaysia \\ murni@iium.edu.my \\ Dept of Information Systems, International Islamic University Malaysia, Kuala Lumpur, Malaysia \\ nurulnuha@iium.edu.my
}

\begin{abstract}
The employment of persuasive technology in education, computing, sales, health, and environment is dramatically increasing. Persuasive technology is powerful in changing the attitudes and behaviours of end users. This paper begins by presenting the ethics of persuasive technology which are relevant to Islamic values and beliefs, and how the concept of persuasion had been applied in Islam practices to influence people. It explores how persuasive technology and its design factors presented in FBM are related to the Islamic practices proven in the Quran and Hadith. Additionally, this paper discusses persuasive technology strategy tools and their activities from Islamic prospective. The paper also examines in depth how Islamic concepts improve the perception of persuasive technology as an interactive computing system which is able to modify attitudes and behaviours. Essentially, this paper also demonstrates how practices and principles of the design factors and strategy tools of persuasive technology have been identified and utilized in early Islamic age. Those principles and strategies are further analyzed from Quran verses and Hadith that are of particular relevance. The conceptual results claim that Islamic principles are a contemporary and universal religion that takes care of the persuasive technology aspects and view of the critically of persuasive technology to Muslim society.
\end{abstract}

Keywords - Persuasive technology, design factors, Islamic viewpoint, strategy tools.

\section{INTRODUCTION}

Persuasion often takes place in our daily communications. Persuasive initiatives are usually associated with attempts that affect our attitudes and behaviours, for instance, to purchase one product or services rather than another, to avoid smoking, to elect any specific political party, to work out more, to fight for environmental protection, animal welfare, and improved schools, or even to consume fruit [1] One of the vital aspects in attitude change is persuasion. Persuasion has typically been considered to be a communication method in which a persuader transmits a persuasive message to the end users using the intention of changing the attitudes or behaviour, although in most cases it leaves the end users with the power of final decision [2].

Computer systems and technologies have gone through rapid development in the earlier days. Technologies have occupied into every scope of our everyday lives, for instance, these days people pay bills, shop, and buy groceries with just a single click. This development is amazingly advantageous whereby it enables individuals to save lots of time. The emergence of technologies has brought to some development of approaches that can persuade or motivate individuals to change their thinking, attitudes and behaviour [3], [4].

Recently, mass media technologies are undertaking significant roles in facilitating the delivery of persuasive messages to donate, buy, elect, and many others. Of late, technology has progressed into highly effective tool by allowing persuasive approaches to be interactively involved rather than one-way communication in everyday lives. Technology can adjust and modify the structure of interaction based on the functions or activities of the persuaded party, including end user inputs, requirements and contexts. This identification has resulted in the studies of persuasive technology. The approaches for creating persuasive products are starting to be much easier to 
implement, as observed in the advancement in online video, social networks and metrics. For that reason, more people and organizations can simply design activities which will give impact to behaviour via technology methods [1], [5].

Islam ought to be a whole way of life, and Muslim shall always relate to the source of Islamic teachings in every single part of his life, and how he should respond in any given situations-that include whenever he deals with persuasive technology situations. It is important to note that two fundamental documents in Islam, Quran and Hadith are neither technological 'how-to' manuals, nor scientific textbook. Alternatively, they are a document of guidelines, which includes general rules appropriate to all times and places. Consequently, it is accurate to express that Quran principles and guidance relate to all fields of life, the technological field being no exception as well as the domain of persuasive technology. The main reason for this research is to present the conception in which Islam and its practices might enhance the approach of persuasive technology and the related design factors. Since the Quran and Hadith are the sources of knowledge and wisdom, Islamic practices are concern about persuasion, strategy tools, and design factors of persuasive technology

This paper attempts to interpret and analyze the nature of persuasion and persuasive technology as introduced in the Islamic worldview by comprehension the Quran verse and Hadith that are of specific relevance. It commences with the background of persuasion definition and the concept of persuasive technology, and the discussion of the ethic of persuasive technology and how it is related and alignment with Islamic ethics and values. Then it is followed by the assessment to the nature of persuasion and persuasive technology in Islamic perspective. It further investigates how principle factors of persuasive technology design: motivation, simplicity, and call for action have been identified and practiced in early Islamic civilization. At the end, seven strategy tools of persuasive technology are presented, which are given serious intention in the Islam practices, and are viewed highly in the context of Muslim society.

\section{BACKGROUND RESEARCH}

\section{A. Persuasion}

Persuasion, in general is the activity or technique to persuade an individual or to influence the person to perform or believe a specific thing (Oxford Dictionary). According to [6], "Persuasion communicative activity usually targets to influence the person who receive the message; which means a motivational message voluntarily presented to the receiver by an idea or behaviour and it is predicted that this message becomes successful in impacting the receiver of that message." Persuasion is part of regular communications. The method of persuasion could be traced back in ancient Greece, when rhetorical speeches were sent to persuade people to carry out certain action. Undoubtedly, persuasion was applied in the past to change the way people think and behave [7]. Consequently, a persuasive method tries to influence people's awareness and behaviour for accomplishing the action which may never occur if people are not exposed to the said persuasive approaches [8].

Persuasion shapes an essential aspect in human interaction. Many people's methods for persuasion are utilized to affect people to behave in a selected manner. Of late, with the aim to raise the impact developed by persuaders on the thoughts of the end users, the persuaders generally utilize technology to form the attitude and behaviour of end users [9].

\section{B. Persuasive Technology}

Fogg [8] asserted that computer systems can be used as persuasive technology and could be designed to change the behaviours and attitudes of people related to health, fitness, education, environment, personal improvement, personal finance, and many more. The recent technology in computers supports in connecting the community and boosting personal relationships to influence the behaviour of end users. In relation to this, Fogg referred the studies of computers being applied as tools for persuasive technologies as "Captology." He provided examples of users of this technology, such as, Amazon, Gold Box Offer, Quitnet.com, RSI Guard, America's Army, and Sportbrain. These entire technologies are produced to have impact on decision of potential customers in buying an item or how workers behave in a particular manner as required by their organization. Fogg [4] defined persuasive technology as "any interactive computing system designed to change people's attitudes and behaviours. Furthermore, computerized software or information systems are designed to reinforce, change or shape attitudes or behaviours or both without using coercion or deception."

Fogg [5] presented a new model with the objective of understanding the behaviour of humans, which indicates that behaviour is influenced by three factors of ability, motivation and triggers. This model is recognized as the Fogg Behaviour Model (FBM). The model assumes that whenever a person wants to achieve a specific behaviour, the person has to be motivated effectively, has sufficient ability to conduct a particular type of behaviour and is triggered to complete the target behaviour. That being said, all three factors need to take place simultaneously, otherwise the target behaviour may not occur. This model will help employees to do the job in teams and encourages 
teamwork culture because employees are able to understand the change in behaviour. Comprehending the change in behaviour could improve employees far better. A variety of methods utilized to produce persuasive products are fairly simple to implement. The ease of use resulted in many new innovations in information technology that includes videos and social networking sites.

A conference in Austria [10] stated that persuasive technology is a tremendously active multi-disciplinary research area that focuses on the improvement, design, and evaluation of collaborative technologies intended to modify end user's awareness or behaviour throughout persuasion as well as social influence that does not involve any kinds of coercion or deception. Additionally, [11] claimed that in qualitative study, for instance, smoke cessation campaign was done in New Zealand by using a game that was designed using "think-aloud" approach to persuade people to quit smoking. The answers were documented and evaluated, which showed evidence of the usefulness of the game to modify the participants' behaviour. In line with that, quantitative scientific researches have also shown the development among lots of end users. For instance, mobile phone software that provides advice on healthy way of life is able to persuade a huge number of patients to improve health-related behaviour changes. Furthermore, Sundar, Oh, Kang and Sreenivasan [12] mentioned that the most obvious aspect of technologies that contributes to persuasion brings out the outcome significantly.

\section{Ethics of Persuasive Technology}

Ethic is definitely the basic principle to regulate a person or group. In other words, ethic is considered as the primary contribution to the community that must be taken care of by any ICT professional [13]. Even with all the obvious advantages of intentions relating to technologies, for instance, applications that helps people to deal with their overweight problems, to inspire people to wash their hands after using the restroom or even to encourage people to drive their automobiles by following safety precautions, ethical concerns are usually put as the most priority in every situations [14]. Assessing ethical worries is an important element in persuasive technology. In the globalization of the ICT technology, it must be considered that values and beliefs are different from one culture to another, so there is no straightforward solution that will certainly satisfy anyone, and no single ethical procedure or group of principles can be easily applicable to every situation. Based on that situation, the crucial element for those in the area of studying, designing or utilizing persuasive technologies is to be more submissive and has understanding of the variety of ethical issues [4]. This is necessary in order to have continuous open discussions on ethical requirements that relates to the benefits and disadvantages of persuasive technology. Since technological enhancement enables more efficient persuasive techniques to be employed, this area continuously generates new ethical challenges. The design of persuasive technology needs to incorporate specifically with ethical rules and morally motivate ICT developers to make responsible designs of persuasive technology [1]

As outlined by [15], the designers of persuasive technology really need to consider, deal with and assume possible obligation for all expected outcomes of its use. It is important to note that the intended outcome of persuasive technology should not be unethical. In addition, designers of persuasive technology must ensure respect for the personal privacy of end users. Persuasive technologies should not deceive end users to perform negative persuasive ends. Apart from that, persuasive technology designers should never make effort to encourage any person to conduct something they themselves will never do.

Nonetheless, Islam has implemented all above ethical procedures and much more in all phases of the Muslim, in which Prophet Mohammed (PBUH) had been sent to the entire world primarily to distribute instructions on Islam and perfect the integrity of "Akklaq". This reveals that ethics and moral values are extremely important in Muslim's life. The Hadith that explains this situation is: "I have been sent to perfect good ethics" (Reported in Sahih Al-Bukari). Hence these values must be incorporated into every point in everyday life as well as in every aspect of ICT as it is not merely the concept of hardware and software, but also peopleware, as well as heartware [16]. To achieve this, a person has to consider whether or not he/she is aligned correctly to ethical principles in making decisions in daily activities. The same concept should be applied in ICT principles. Therefore, designers of persuasive technology, which is a component of ICT, need to instill moral intentions when developing products that are aligned with the fundamental principles of Islamic ethics.

\section{PERSUASION IN ISLAM}

Persuasion constantly concentrates on mankind, which is the highest level of creatures in the whole world as Allah (S.W.T) specifically granted the brain to them compared to other creatures. As Allah (S.W.T) said: "And We have certainly honored the children of Adam and carried them on the land and sea and provided for them of the good things and preferred them over much of what We have created, with [definite] preference" [Quran 17:70]. Consequently, Prophet Mohammed (PBUH) was sent to the people primarily to influence them to diverse into Islam by employing the most significant miracle, the Holy Quran and Sunnah. Allah (S.W.T) created the mankind simply to worship Him when Allah 
(S.W.T) said: "I did not create jinn and humans except to worship Me" [Quran 51:56]. Therefore, all the different approaches of persuasion in Islam are utilized to accomplish one main thing, which is to worship Allah (S.W.T) [17].

Persuasion is the final purpose of any communicational activity and the objective of persuasion is to affect people's attitude and behaviour. Surely, Quran has this sort of characteristic, which is to influence the people and develop a new attitude into their mind. Thusly, the real mechanisms of influence in the Quran are the meanings in the words and phrases. Quran words are not only persuasive, but in addition they influence people in speaking with respect to other people's needs and provide answers to various questions. One of the most important factors in persuasion is to produce the message so that it is easier for people to understand. As seen in the Quran, it had been revealed in the form of sections, verses and expresses explanations by subject or question, which makes it understandable for people. The Prophet Mohammed (PBUH) in his sermon, also targeted on very effective conversation to persuade and influence people to shape into new attitudes and behaviours. This process has been confirmed in the many Hadith reported about him choosing the most effective and respectful words or phrases to transfer his message while being attentive to the beauty, wisdom and knowledge in his sermons and conversations [18], [19].

Persuasion in Islam is a practice between two parties, when one side attempts to modify the other or change another party's awareness on a particular behaviour, such as giving donations, praying promptly, and looking after the parents [20]. Islamic principles remarkably highlight the employment of a persuasive method to boost the creation of robust relationships between humans and Allah (S.W.T) throughout commitments to his instructions and by performing appropriate deeds to acquire the reward from Allah (S.W.T). Among examples of the behavior are; staying away from sins by not committing any kind of prohibited deeds, carrying out imposed worships and establishing great relationships within oneself and others. This is evidenced by the saying of Allah (S.W.T): "Let there be a group among you who call ?others? to goodness, encourage what is good and forbid what is evil-it is they who will be successful" [Quran 3:104].

Rahman [21] stated that from the religious viewpoint, dialogue and persuasion are applied as moral approaches in Islamic missionary work or "Dawaah." Dawaah means "invitation," or known as actions of worship by explaining to the audience matters concerning religion understanding and practices rather than manipulating or forcing them to be involved in it. Allah (S.W.T) said: "Invite? all? to the Way of your Lord with wisdom and kind advice and only debate with them in the best manner" [Quran 16:125]. Thus, Islam declines the usage of persuasion to force people to transform from their religion and belief and be Muslims, simply because no coercion should be imposed in the religion, which is evidence that Islam has considerate principles in its practices. Allah (S.W.T) said: "Had your Lord so willed? O Prophet? all? people? on earth would have certainly believed, every single one of them! Would you then force people to become believers?" [Quran 10:99].

\section{Persuasive teChnology in ISLAmic PeRspective}

Muslims are well guided throughout the word of Allah (Quran) and the Prophet Mohammed (PBUH) Hadith, thus encouraging the Muslim community to develop a society with high moral values. Consequently, this order has influenced Muslims to perform good deeds through decades. Therefore, it is strongly suggested that ICT leading guidelines to be dependent with the Islamic viewpoints on moral issues, which are derived from the Quran and Hadith [16].

In Islam, information and communication are viewed as critical and beneficial resources to obtain knowledge and to accomplish highly effective Islamic community. This firm belief is accelerated with the usage of ICT [18]. Basically, ICT is formed from three components, specifically; peopleware, hardware, and software. However, to date, the aspect of peopleware is not frequently explained, despite the fact that heartware is the most significant component associated with peopleware. Without proper comprehension of heartware, understanding ICT will not be completed [22]. In a similar way, designers of persuasive technology need to possess the intention to generate persuasion products that represent Islamic ethics to influence the end users in accurate ways that will lead to having end results that are ethically connected with Islamic principles. On the other hand, end users really need to comply with Islamic principles when they have been persuaded to avoid any kind of actions against Islamic ethics. Prophet Mohammed (PBUH) said: "Beware, in the body there is a piece of flesh; if it is sound, the whole body is sound and if it is corrupt the whole body is corrupt, and hearken it is the heart" (Sahih Muslim: Book 22, Hadith 133).

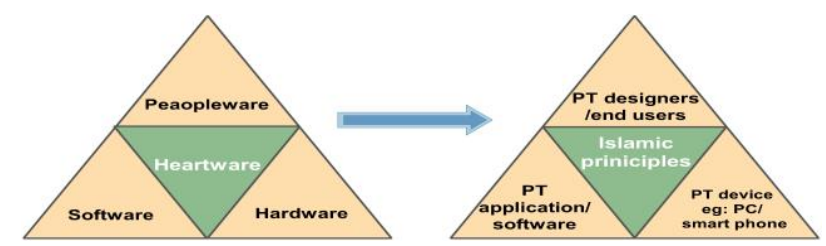

Fig.1 ICT components for persuasive technology in Islam (PT: Persuasive Technology) 
As displayed in Figure 1, ICT components indicate how persuasive technology reflects these components and heartware (Islamic principles), that are the most essential components for the designers. The heart must be purified to acquire guidance and wisdom from Allah (S.W.T), as the heart is extremely important, for it can easily differentiate what is correct and incorrect in human behaviour.

\section{PRINCIPLE FACtors of PERSUASIVE TECHNOLOGY DESIGN IN ISLAMIC PERSPECTIVE.}

Based on the study conducted by [5], a model that comprehend human being behaviour, which is called the Fogg Behaviour Model (FBM) was developed. This model is considered as a significant factor for persuasive technology designers to generate products that can change user attitude and behaviour. Moreover, the FBM influences users largely by employing the three factors which are; motivation, simplicity (ability) and call for action (trigger) as can be seen in Figure 2. These three factors are described from the Islamic point of view in the next subsection.

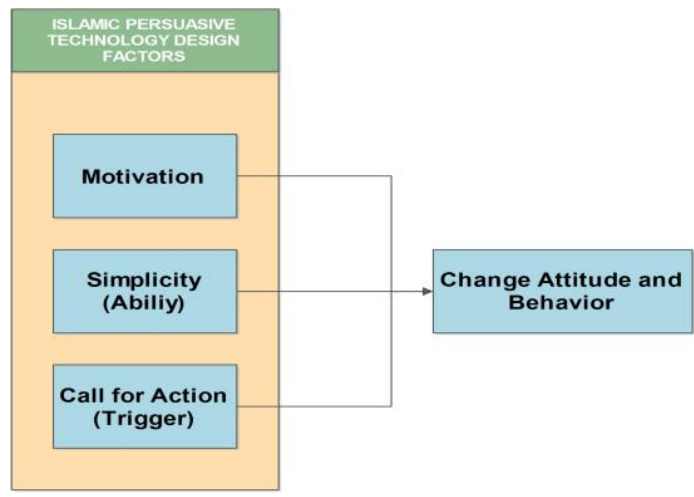

Fig. 2: Persuasive technology design factors in Islam

\section{A. Motivation}

The first factor identified in FBM [5] is motivation, which indicates the reason behind end users' actions or behaviours in a specific way. [23] described motivation as the desire inside a person which really encourages the performance of a particular action. Clearly, each individual has the desire and wants to accomplish in life. Subsequently, individuals need to possess motivation as a persuasion to achieve their targets. It is a known fact that humankind requires some important necessities to live, such as food, house, money, car as well as other natural needs, whereby they need to work to obtain the needs. For Muslims, working is a part of worshipping Allah (Ibadan) and ought to be the main motivation in carrying out their commitments as servants of Allah.
Motivation is known to be the central point in Islamic basic principles, which absolutely identifies and emphasizes the significance of motivation in human activity. Motivation asserts that people's behaviour is governed by internal intensions, drives and motives. In this particular regard, the Prophet Mohammed (PBUH) said: "The acts depend on intentions. A man will get whatever he had intended for" (Sahih Muslim, Book 33, Hadith 222). The faith (Iman) is the vital motivator which reveals the actual faith and belief in Allah, as his messenger, his Book and the Day of Judgment. Furthermore, Iman is an important and most valuable motivational drive in the life of a Muslim. Generally, all actions of a true Muslim represent his/her Iman. Hence, Iman provides a powerful Islamic motivational factor to lead and influence people's behaviour in life [24]. Each Muslim must submit to Allah, as the Quran ordered Prophet (PBUH) to do: "Say (O Muhammad SAW): "Verily, my Salat (prayer), my sacrifice, my living and my dying are for Allah, the Lord of the worlds" [Quran 6:162].

The concept of fear of Allah, in particular, is proven by the act of following his instructs and orders as well as preventing disobedience. The motivation of fear is definitely the human being feeling that enables people to avoid risks, severe situations or experience and resolves them as well. As a result, people who adhere to the orders of Allah are going to be rewarded and those who disobey will be penalized. The Prophet Mohammed (PBUH) and the other messengers of Allah were sent with glad tidings and warnings, as mentioned in the Quran: "And Allah sent messengers with glad tiding and warnings" [Quran 2:213].

Evidently, the earlier Quran verses generated the real internal motivation and self-direction throughout persuasive technology for designers and end users. A true Muslim performs all sorts of actions in persuasive technology process, while having the basic intention of looking towards the reward from Allah by following appropriate orders and preventing incorrect activities. An individual who believes actions are very important parts of worship will surely exhibit a truly higher level of motivation and persuasion in persuasive technology. This kind of belief is practiced in their ways of influencing end users, designers, and the Islamic community at an advanced level of morals and values aligned with Islamic concepts.

\section{B. Simplicity (Ability)}

The second factor in FBM [5] is ability, which means the simplicity of performing the target behaviour. Typically, raising the ability helps to make the behaviour less difficult and simpler to complete. Simplicity is a crucial factor in persuasion. Humankind has natural human drive to use less effort, which means people are generally impassive. For 
example, when a process involves simple task to proceed, such as clicking buttons several times at a computer or other devices, humans are more inclined to carry out the process straight away. However, if the processes are complex and require many steps of actions, humans will be most likely to stay away from the process or postpone the action [25]

Islam is a religion for all, every individual, anywhere and for all ages. The emergence of Islam is neither to control people, nor incur costs, nor struggle with absurd rules to follow, instead, it was Godsend to achieve contentment for every human being, as well as to take away hardship, embarrassment, and difficulties. Allah (S.W.T) said: "Allah intends for you ease and does not intend for you hardship" [Quran 2:185]. The messenger of Allah (PBUH) also said: "Religion is very easy and whoever overburdens himself in his religion will not be able to continue in that way. So you should not be extremists, but try to be near to perfection and receive the good tidings that you will be rewarded; and gain strength by worshipping in the mornings, the afternoons and during the last hours of the nights" (Sahih al-Bukhar, Book 2, Hadith 32). Therefore, the fundamental characteristic of Islam is based on the belief that the religion is not difficult, but it is indeed permissive, simple and easy. In fact, facilitation and getting rid of difficulty is the foundation for the generality and internationality of Islam. Along with such attributes, adequate care of humankind is important, to which Islam does not complicate the performance of worship. For example, Muslims who travel or sick have considerations in practices, which includes fasting during the holy month of Ramadan. Allah (S.W.T) offered them the permission to postpone their fasting to other days in order to ease the condition for people to endure the hardship during their travels.

With examples shown above, it is clear that Islam practices the component of simplicity in inspiring people to appropriately worship Allah (S.W.T) without any difficulties. In line with the discussion in this study, in order to persuade end users to use persuasive technology, designers must include simplicity in their method to generate uncomplicated and simple process to achieve the targeted behaviour. Having mentioned all these, the method and target behaviour of persuasive technology can however be challenging. Simplicity in persuasive technology product displays a considerable concept of Islamic values which could help end users and designers in generating very efficient products and solutions in persuasion.

\section{Trigger (call for action)}

The final factor in FBM [5] is trigger (call for action or behaviour activation). Without an applicable trigger, behaviour will never occur even with utmost simplicity and high motivation. Reported by Longman Dictionary, trigger means "to make something happen very quickly, especially a series of events." Hence, for the behaviour to take place, it needs to be activated by applying adequate behaviour activation, which is trigger. Furthermore, the trigger can be something that is requested to the people to carry out the action which might come in various forms, such as prompts, call, cues, and many other ways. Chen et al. [26] asserted that trigger plays the main factor for encouraging targeted behaviour.

In Islamic viewpoint, calling for action or behaviour activation appears in many Islamic practices. During the era when Islam first came, through the Prophet (PBUH), the religion persuaded people to perform righteous deeds and worship Allah whereby it involved the encouragement throughout variety of methods. Allah (S.W.T) said: "The month of Ramadhan [is that] in which was revealed the Qur'an, a guidance for the people and clear proofs of guidance and criterion. So whoever sights [the new moon of] the month, let him fast it" [Quran 2:185]. This is a clear example of trigger, where the sighting of the moon on the first day of Ramadan is considered as a trigger or calling to the Muslim to start fasting. In this case, fasting during Ramadhan begins when Muslims observe the moon, however, the fasting period breaks once the moon of the following month, Shawal is sighted. As Prophet Mohammed (PBUH) said: "Observe fast on sighting it (the new moon) and break (fast) on sighting it (the new moon), but if the sky is cloudy for you, then complete the number (of thirty)" (Sahih Muslim, Book 13, Hadith 21).

The above-mentioned example reveals how Islam relies on a trigger to call people to conduct target behaviour. The behaviour activation in Islamic practices is used as a main principle to assist Muslims conduct worship at proper time. The call (Athaan) which happens five times a day reminds Muslims of the right time of prayer. This kind of reminder helps them to perform their prayers punctually. A trigger in persuasive technology design has identical function in triggering and making the behaviour occur. Undoubtedly, Islamic values, that include call to action, have already been accelerated with the usage of persuasive technology in developing productive systems for persuasion and the enhancement in the lives of the Islamic society with the occurrence of the needed behaviour.

Obviously, the integration of these factors; simplicity, motivation, and call for action (trigger) can be found in a very significant practice in Islam which is prayer (Salah). First, the motivation is to acquire the reward from Allah to carry out prayer. Likewise, they are driven by the fear of incurring penalties from Allah if they purposely leave the prayer. Second, simplicity in prayer refers to the situation where Muslims can easily pray at any place in the world, and 
travellers are able to accumulate their prayers to two prayers at one time to make them short. Finally, the call for action (trigger) is clear in the Athaan or prayer call, which reminds Muslim people to conduct their prayers on time.

\section{Persuasive technology StRategy tools from an ISLAmic VIEWPOINT}

Fogg [4] determined persuasive technology strategies as interactive computer tools that are designed to change attitudes or behaviours or both to make desired outcomes simpler and easier to achieve. Persuasive technology strategy tools have been identified to help, affect, influence, encourage, motivate and educate end users regarding their awareness and behaviour [9]. Fogg asserted that seven strategy tools are generally utilized in persuasive technology tools which include reduction, tunneling, tailoring (customization), suggestion, self-monitoring, surveillance, and conditioning (reinforcing) [27],[28]. However, the conception of persuasive technology strategy tools has been long identified in Islamic principles and practices from Quran and Hadith. These strategies tools demonstrate and confirm to Islamic viewpoint in the following sections:

\section{A. Reduction}

Reduction indicates the use of computing technology to reduce difficult behaviour to facilitate the tasks and influence end users to achieve the target behaviour. Reduction technologies help to make target behaviours simpler by reducing complicated activities to simpler ones such as reducing it to only a few easy steps. As an example, if a person buys items on Amazon.com, he/she is able to sign up for "one-click" shopping. Using a single click of a mouse, the items bought are charged automatically to the credit card, packed up, and shipped off. The reduction strategy behind "one-click" shopping is most effective in motivating customers to purchase things [4], [29].

On the other hand, Islam has clearly distinguishes the reduction on Muslim deeds to lessen the difficulties of performing any action to worship Allah. The reduction makes the behaviour easy, simple and very persuasive to perform the action as Allah (S.W.T) said: "And Allah wants to lighten for you [your difficulties]; and mankind was created weak" [Quran 4:28]. Therefore, Islam religion has naturally been practicing the value of lightening and reducing the effort of human being's actions. Furthermore, Islamic practices do not include any kind of hardship, in which Allah does not load any person with heavy responsibility that the person cannot bear. For example, in the case where a person does not have the capability to perform a particular behaviour, Allah will not burden the person to perform the task. Allah (S.W.T) said: "Allah does not charge a soul except [with that within] its capacity" [Quran 2:286].

\section{B. Tunnelling}

Tunnelling refers to the act of applying computing technology to guide end users through a procedure or experience that can provide the opportunity to persuade along the way. The system guides end users in their mind set change process by providing steps which consequently bring them towards any targeted behaviour. Likewise, computer systems function is seen as persuasive tools, whereby it simply leads the end users step by step through established series of events or actions [4], [29]. For instance, computer software installation provides excellent illustration of tunnelling technology. In most cases, installing software today is straightforward; the computer guides the user throughout the process, step by step. During the installation tunnel, user can choose which parts of the application to install and where.

Form Islamic perspective, tunnelling was the way that Allah (S.W.T) and the Prophet (PBUH) taught the whole mankind how to perform particular action in proper manner by providing series of actions and steps that persuade people to perform the behaviour. For example, by learning the Quran, it teaches the Muslim how to conduct the correct prayer's ablution by reading and understanding the sequence of steps in ablution. Allah said: "O you who have believed, when you rise to [perform] prayer, wash your faces and your forearms to the elbows and wipe over your heads and wash your feet to the ankles" [Quran 5:6]. Additionally, Prophet Mohammed (PBUH) provided the right steps for all Muslim on how to pray in proper manner which was mentioned in Hadith of the abuse in one's prayer [Sahih alBukhari: Book 79, Hadith 25].

\section{Tailoring (Customization)}

Tailoring is the situation where information offered by computing technology will be more persuasive when it is tailored to the end users' requirement, personality, interest, usage context, or any other aspects related to the end user to change their attitudes or behaviours [4]. The system provides customized information for its user groups which would persuade them to carry out certain behaviour [30]. Tailoring technologies help to make life simpler for computer users who usually prefer not to struggle through amounts of generic information to discover what is related to them. For instance, MS Word processing software may propose the improvement of working vocabulary by requesting the user to learn a word every day when the program has realized that the user is prone to use small group of words [4].

Undoubtedly, Islam has the principle of customization in every aspect of Islamic instruction. This is certainly 
evidenced by the timely distribution of the Quran verses, whereby the Holy Quran that was revealed by Allah to Prophet Mohammed (PBUH) was distributed in different times and places based on the reason and the situation that occurred during that moment. In timely basis, the verses of Quran were delivered to provide certain information to particular people related to the event or case. Consequently, each chapter (Surah) in Quran has special information that communicates with particular group of people and explains special issues. For example, chapter (Surah) An-Nisaa in the Quran has all instructions regarding inheritances, which clarified the issue of how to distribute the inheritances fairly to the inheritors. This chapter illustrates this issue clearly for those connected to this case. Thus, Islam has customised (tailored) the information and instruction to persuade individuals to perform the behaviour that is necessary for them.

\section{Suggestion}

Suggestion technology is an interactive information system product that suggests a behaviour at the most appropriate time. Studies have proven that systems providing suitable suggestions will significantly have greater persuasive power when offered at appropriate moment [4], [30]. For example, based on experience, certain people are much more motivated to perform certain behaviours at specific times more than others, therefore, suggestion technologies are developed to determine the appropriate times and later remind the end users to carry out the behaviours [27]. For instance, Speed Monitoring Awareness and Radar Trailer that can be positioned at the side of the road to monitor the speed of oncoming cars and display the cars' speed on a large output device, as well as show the speed limit for the street. As a result, drivers reevaluate their driving behaviour based of the suggestion from Radar Trailer. This allows the drivers to create the decision about the speed at the right time if they happen to drive too fast.

Prophet Mohammed (PBUH) taught Islamic values and instructions to the companions by using suggestion at appropriate moment to perform right behaviour in most of his sermons and messages. For instance, after the terms of the Hudaybiyah peace and returned to Al-Madinah without entering Mecca, the Muslims considered what happened as a kind of indignity. When they were requested by the Prophet Mohammed (PBUH) before returning to AlMadinah to shave their heads and slay the sacrifice animals, his companions refused to do so. Then the messenger of Allah did not talk to any of them, started to slay his own sacrifice animal and shaved his head, so when the companions saw that, they did the same as the suggestion of behaviour from the Prophet at the proper time. Thus, the suggestion strategy was implemented effectively in Islam which is to persuade people to perform appropriate behaviour at the best moment

\section{E. Self-monitoring}

Self-monitoring technology enables people to monitor themselves to change their attitudes or behaviours to achieve an established goal or outcome. The objective of self-monitoring is to remove the hassle of calculating and monitoring performance or status. This technology simplifies the concept for individuals to be aware of how well they are performing against the target behaviour, while enhancing the probability that they can continue to generate the behaviour. One of the good examples of selfmonitoring technology designed to persuade people to change behaviour is heart monitor watches. Usually placed on the body, the product monitors a person's heart rate during exercising. With these wearable computers, users can monitor their heart rate precisely and easily [4], [30].

At the same time in Islam, self-monitoring is the basic principle for every Muslim, where practitioners monitor themselves to ensure that they avoid committing any sins and continues to conduct good deeds. Allah said: "Rather, man, against himself, is well aware of himself" [Quran 75:14]. Obviously, it is a clear instruction from Allah to monitor oneself of what is committed or not, and even when the person comes with excuse of his/her sin, it does not bring any benefit. In agreement to this, Omar Bin Al-Khattab said: "Watch yourselves before you are judged". Eventually, selfmonitoring is the Islamic concept that encourages and persuades people to change their attitude and behaviour to perform good deeds and prevent them from committing sins.

\section{F. Surveillance}

Surveillance technology is commonly described as any computing technology that allows one party to monitor the behaviour of another with the aim to change the behaviour in a certain way in which by doing so, increases the probability of achieving the desired result [4]. For example, in that case, end user's behaviour is observed and monitored by other people [28]. Surveillance technology is the most frequently used in today's marketplace. There are applications for monitoring precisely how employees use the internet, how mobile phone supports employees serve their clients, how teenagers drive, and much more. AutoWatch is an example of surveillance technology which is a computer system that allows parents to observe the driving behaviour of their children.

It is important to note that surveillance is the highest level of faith in Islam. When a Muslim realizes that Allah (S.W.T) watches over and observes every single action, then 
the attitude and behaviour will be changed to attain happiness in this life and hereafter. Allah said: "And Allah is Ever a Watcher over all things" [Quran 33:52]. Also, Allah said: "Does he not know that Allah sees 'all?" [Quran 96:14]. Accordingly, knowing that surveillance from Allah (S.W.T) of our actions and behaviour would be very effective and persuasive method to change one's attitude and behaviour to carry out appropriate actions and prevent making sinful mistakes.

\section{A. Conditioning (Reinforcing)}

Conditioning technology refers to an interactive computer system which uses the concepts of positive reinforcements to shape complicated behaviour or transfer current behaviours into habits [4]. In order to be most efficient, the conditioning has to take place soon after the performance of the behaviour. Additionally, for positive reinforcement to successfully generate additional similar behaviour, the end users must have some interest in receiving positive feedback, whereby they have to be aware about the connection between target achievement and rewards [27]. Video games offer reinforcements by means of sounds and visuals. The rewards are also available in different ways; through the accumulated points, rankings of higher scores, progression to a higher level, and more.

Positive reinforcements have been noticeably mentioned in many verses in Quran and Hadith which encourage people to reinforce their behaviour that will later transfer to be habit by offering positive feedback. Allah said: "The example of those who spend their wealth in the way of Allah is like a seed [of grain] which grows seven spikes; in each spike is a hundred grains. And Allah multiplies the reward even more "to whoever He wills" [Quran 2:261]. The meaning of this verse is that Muslim who conducts charity will be rewarded hundred to seven hundred times and could be more for his/her kindness. Hence, reinforcement (conditioning) is the Islamic principle to persuade Muslim people to change and reinforce the behaviour when they are aware of the connection between target behaviour and rewards.

\section{VII.CONCLUSION}

Islam is considered as a complete set of guidance for a lifetime, in which it supports the value of technologies, information technology as well as acknowledges the significance of persuasive technology. Efficiently, Muslims have been motivated by Islam to implement any sort of approaches and resources accessible that might increase in the betterment of their attitudes and behaviours. The favorable prospective of ICT is usually enhanced by essential evaluation and assessment of their utilization in Muslim societies and culture, as well as by assessment based on the conceptual principles and values of Islam. Persuasive technology can be seen as a necessity to have very high benefit of achieving target behaviour. The Quran and Hadith highlight ethics of persuasive technology. Moreover, design factors in principles of motivation, simplicity and trigger have already been identified and inherited from Islamic values and principles as all factors have been mentioned in many Quran verses and Prophetic Hadith. Similarly, it is also important to note that seven strategy tools of persuasive technology have been Islamically recognized as the origin and foundation of the strategy tools are derived from Islamic practices and values.

Persuasion is evidently related in influencing people's behaviour by using various methods. The adoption and implementation of principle design factors and strategy tools of persuasive technology in Islamic practices and values will improve the persuasive products to target needed attitude and behaviour. In addition, developing a persuasive technology product which depends on Islamic guidelines can certainly help designers in producing very efficient systems to enhance the Islamic community which in later stage, benefits the end users. Accordingly, it is very accurate to conclude that Islam encourages, adopts, and practices extensive principles of persuasive technology. As for future recommendation, it is hoped that researchers have the ability to examine in depth the effectiveness and the impact of implementing Islamic principles in persuasive technology design factors and strategy tools.

\section{REFERENCES}

[1] W. IJsselsteijn, Y. De Kort, C. Midden, B. Eggen, and E. Van Den Hoven, "Persuasive technology for human well-being: setting the scene," in International conference on persuasive technology, 2006, pp. 1-5.

[2] M. Harjumaa and H. Oinas-Kukkonen, "Persuasion Theories and IT Design," in International Conference on Persuasive Technology, 2007, pp. 311-314.

[3] M. A. Bawazir, M. Mahmud, N. N. A. Molok, and J. Ibrahim, "Persuasive Technology for Improving Information Security Awareness and Behavior: Literature Review," in International Conference on Information and Communication Technology for The Muslim World(ICT4M), 2016 6th International Conference, 2016, pp. 228-232.

[4] B. Fogg, Persuasive Technology Using Computers to Change WhatWe Think andDo. Ubiquity, 2002.

[5] B. Fogg, "A behavior model for persuasive design," Proc. 4th Int. Conf. Persuas. Technol. - Persuas. '09, p. 1, 2009.

[6] H. Moradi, persuasion and communication. Tehran,iran: Saghi, 2010.

[7] J. M. Hogan, "Persuasion in the rhetorical tradition," SAGE Handb. Persuas. Dev. Theory Pract., p. 1, 2012.

[8] B. J. Fogg, "How to Motivate \& Persuade Users," CHI 2003 New Horizons, 2003.

[9] H. A. Qudaih, M. A. Bawazir, S. H. Usman, and J. Ibrahim, “Persuasive Technology Contributions Toward Enhance Information Security 
Awareness in an Organization," Int. J. Comput. Trends Technol., vol. 10, no. 4, pp. 180-186, 2014.

[10] M. Almaliki and R. Ali, "Persuasive and Culture-Aware Feedback Acquisition," in International Conference on Persuasive Technology, 2016, pp. 27-38.

[11] S. Halko and J. A. Kientz, "Personality and Persuasive Technology: An Exploratory Study on Health-Promoting Mobile Applications," in International conference on persuasive technology, 2010, vol. 6137, pp. 150-161.

[12] S. S. Sundar, J. Oh, H. Kang, and A. Sreenivasan, "How Does Technology Persuade?," SAGE Handb. Persuas. Dev. Theory Pract., p. 388, 2012.

[13] A. Asadullah, B. Yerima, and Y. Aliyu, "The Ethics of Information and Communication Technology : An Islamic Overview," vol. 4, no. 2, pp. 45-49, 2014.

[14] P. . Verbeek, "Persuasive Technology and Moral Responsibility Toward an ethical framework for persuasive technologies," Persuasive06, pp. 1-15, 2006.

[15] D. Berdichevsky and E. Neuenschwander, "Toward an ethics of persuasive technology," Commun. ACM, vol. 42, no. 5, pp. 51-58, 1999.

[16] M. F. Noordin, "Application of Privacy, Security and Ethics in Islamic Concerned ICT," Middle-East J. Sci. Res., vol. 14, no. 11, pp. 1548-1554, 2013.

[17] A. Rezeq, theories and methods of persuasion. Lebanon: Dar Alsafoah, 1994.

[18] S. Zulhuda, "Information security in the Islamic perspective: The principles and practices," Proceeding 3rd Int. Conf. Inf. Commun. Technol. Moslem World 2010, p. H-33-H-39, Dec. 2010.

[19] I. Fathollahi and I. Kamely, "Persuasion process in Quran," Int. Res. J. Appl. Basic Sci., vol. 3, pp. 2657-2666, 2012.

[20] I. Alhmedan, persuasion in Islam. Saudi Arabia: Alemmam Mohammed bin Saud Islamic University, 2007.
[21] K. A. Rahman, "Dialogue and persuasion in the Islamic tradition: Implications for journalism," Glob. Media Journal, Can. Ed., vol. 9, no. 2, pp. 9-26, 2016

[22] M. F. Noordin, ICT and Isalm. Malaysia: IIUM press, 2009.

[23] Z. Khair, N. Ahmad, and M. azhar abd Hamid, "Motivation in Islamic Perspective : A Review," Res. gate, 2017.

[24] R. Amin and M. G. Mohiuddin, "MOTIVATING PEOPLE IN ORGANIZATIONS : THE ISLAMIC WAY," Int. J. Islam. Manag. Bus., vol. 2, no. 2, 2016

[25] B. J. Fogg, "Mass interpersonal persuasion: An early view of a new phenomenon," in International Conference on Persuasive Technology, 2008, pp. 23-34.

[26] Y.-X. Chen et al., "Opportunities for persuasive technology to motivate heavy computer users for stretching exercise," in International Conference on Persuasive Technology, 2014, pp. 25-30.

[27] R. Khaled, J. Noble, and R. Biddle, "An Analysis of Persuasive Technology Tool Strategies," Iwips, pp. 167-173, 2005.

[28] S. S. Ferebee, "Successful persuasive technology for behavior reduction: mapping to fogg's gray behavior grid," in Persuasive Technology, Springer, 2010, pp. 70-81.

[29] H. Oinas-Kukkonen and M. Harjumaa, "A systematic framework for designing and evaluating persuasive systems," in Persuasive technology, vol. 5033 LNCS, 2008, pp. 164-176.

[30] H. Oinas-kukkonen and M. Harjumaa, "Communications of the Association for Information Systems Persuasive Systems Design: Key Issues, Process Model , and System Features Persuasive Systems Design : Key Issues , Process Model , and System Features," Commun. Assoc. Inf. Syst., vol. 24, no. 28, pp. 485-500, 2009. 